\title{
La arrogancia de la Razón
}

\author{
MARCELO DASCAL \\ Universidad de Tel Aviv
}

El examen de algunos momentos de la historia de la Razón en Occidente revela una propensión de la Razón a atribuirse más de lo que se justifica en cada momento de su desarrollo, es decir, una tendencia a la arrogancia. Una estrategia recurrente para proteger a la
Razón de posibles o reales críticas, y así preservar su postura arrogante, es la que llamo «aislamiento». Cuatro variantes de esa estrategia -la "departamentalización", la "profundización", la "trascendentalización», y la «metodificación» de la Razón-son analizadas.

\begin{abstract}
ARROGANCE: The taking of too much upon oneself as one's right; the assertion of unwarrantable claims in respect of one's own importance; undue assumption of dignity, atthority or knowledge; aggressive conceit, presumption or haughtiness.
\end{abstract}

[Oxford English Dictionary]

\section{Introducción}

Estamos sin duda viviendo uno de los momentos de triunfo y expansión del "Occidente», comparable quizá a la conquista del Nuevo Mundo en el siglo XVI. Por casi todas partes -en la Unión Soviética de Gorbachov, en la Rumania post-Ceaucescu, en el Brasil de Fernando Collor de Mello, en la Nicaragua de Violeta Chamorro- parece obvio que la ruta hacia el progreso, hacia la liberación del hombre, hacia una vida mejor, es clara: reproducir lo que ha tornado posible esos logros en los países adelantados de Occidente.

Por casi todas partes parece también haber unanimidad en considerar a la "democracia", la "economía de mercado" y el "desarrollo científico y tecnológico", si no como los mismos logros que hay que imitar, por lo menos como condiciones necesarias ( $y$ tal vez suficientes) para llegar a ellos. Se presupone así que esos ingredientes de alguna forma expresan algo esencial a la "Civilización Occidental», no compartido (en. su conjunto) por otras civilizaciones, algo que además corresponde a lo que de mejor hay o puede haber en la naturaleza humana. Ese "algon, al que todo apunta, esta íntimamente relacionado con la idea de que es en la Civilización Occidental donde la Razón, característica esencial y dis- 
tintiva del hombre, ha podido manifestarse en su forma más plena. Los logros del Occidente serfan, por lo tanto, debidos principalmente al ejercicio y desarrollo de la Razón, a su aplicación a un número cada vez mayor de sectores de la actividad humana. Por supuesto el Occidente no ha resuelto todos los problemas que afronta el hombre. Tampoco puede vanagloriarse de poseer el saber necesario para resolverlos de inmediato. Pero sí sabe, así se supone, qué es lo que tiene que hacer para adquirir el saber que le permitirá resolver, aunque sea gradualmente, todos los problemas que se le planteen: seguir desarrollando y aplicando, en forma cada vez más amplia, su Razón.

Paradójicamente, en el momento mismo de su triunfo político, la Razón Occidental es el blanco de cuestionamientos y ataques por parte de los que tradicionalmente han sido sus más fieles defensores: los filósofos de Occidente. La reciente ola de relativismo filosófico, en sus varias formas, ha resucitado viejas dudas y agregado otras nuevas respecto a nuestra irrestricta confianza en la Razón. Los relativistas han tratado de demoler nuestra creencia en una Naturaleza Humana única e inmutable, en una Razón universal, en la posibilidad de proveer fundamentos sólidos para conocer el mundo y actuar en él, en el valor de la ciencia y de la tecnología, y en la factibilidad de una disciplina privilegiada - la Filosofía- cuya tarea sería la de elaborar y aclarar las normas por las cuales se deben regir todo conocer y actuar racionales. De esta manera, el relativismo parece corroer, desde dentro, la base misma de la supuesta superioridad del Occidente, y así poner en duda la aceptación incondicional del modelo occidental como digno de imitación.

El enemigo directo al que se enfrenta el relativismo contemporáneo cs la Razón Moderna. La principal estrategia que éste emplea consiste en desenmascarar las pretensiones de dicha Razón como siendo nada más que fruto de su arrogancia. A cada uno de los supuestos logros o capacidades de la Razón Moderna, contraponen los relativistas su indefendibilidad. A la lista del párrafo anterior podríamos agregar, por cjemplo: la idea de que hay un conjunto de reglas, un Método, que permite llegar al saber, y que le toca a la Razón descubrir y aplicar esas reglas; la tesis de que ese Método - sean cuales sean sus detalles-es superior a cualquier otra fuente de saber, no basada en la Razón; la confianza en la capacidad de la Razón para unificar y hacer coherente todo nuestro saber y formas de acción; la creencia en la habilidad de la Razón para autoperfeccionarse irrestrictamente 0 , cuando sea necesario, reconocer y fijar sus propios límites; la certidumbie de que la Razón, cuando es ejercida con los cuidados necesarios, se alza sobre lo contingente, rescatando de la propia diversidad y variabilidad histórica o cultural principios absolutos y universales. Al mostrar la injustificabilidad de cada una (y del conjunto) de esas autoatribuciones de la Razón Moderna, el relativismo 
piensa estar revelando claramente su carácter arrogante, es decir, el hecho de que ella se atribuye a sí misma logros o capacidades que van siempre más allá de lo que le está legítimamente autorizado. La expresión "Razón Moderna» sugiere de por sí la posibilidad de que lo que hemos venido llamando «Razón» no corresponda a un único contenido, transhistórica y transcontextualmente constante. Gilles Granger, en su monografía La Raison, señala que

[...] la raison ne se peut définir utilement que dans un contexte; elle n'est pas une notion simple et immédiatement donnée, mais l'un des complexes culturels les plus riches de sens qui puissent s'offrir a l'obscrvation et a la réflexion [Granger, 1958, p. 7].

Pero ¿no sería acaso la arrogancia una característica constante, tal vez necesaria, si no de la Razón tout court, por lo menos de la Razón Occidental?

En este trabajo quiero echar un vistazo a algunos episodios de la historia de la Razón en Occidente con el fin de examinar las formas que toma su arrogancia. Si es que de este estudio; admitidamente somero y selectivo, se pueden sacar conclusiones, serían las siguientes: a) la Razón ha sido arrogante desde el primer momento de su aparición en la «historia intelectual de Europa ${ }^{1}$ y no solamente en su forma de "Razón Moderna»; $b$ ) cuando ha sido criticada por su arrogancia, la Razón no se ha rendido a las críticas, sino que se ha automodificado para hacerles frente; c) algunas de esas modificaciones, que han consistido en adoptar una postura más modesta, han llevado, sin embargo, a nuevas formas de arrogancia; $d$ ) es posible identificar estrategias que se repiten en el conflicto entre la Razón y sus críticos a lo largo de la historia; y, finalmente, e) todo eso ofrece una perspectiva capaz de aclarar la significación de las batallas de ese conflicto milenario que se traban en el presente momento.

\section{Primer apogeo}

Según las historias convencionales de las ideas y de la filosofía, la Razón emerge en la historia intelectual de Europa en Grecia, en los siglos v y v a.C. Sus primeros representantes serían aquellos pensadores griegos que tratan de ir más allá de las apariencias resultantes de la experiencia directa con el fin de explicar la diversidad de los fenómenos en términos de algún principio unificador. Esos pensadores construyen teorias sobre la naturaleza subyacente de las cosas y confían en su capacidad de defender sus especulaciones teóricas por medio de argumentos, y no solamente invocando la autoridad de alguna tradición. El conjunto de esos trazos distingue al incipiente uso de la Razón de su principal competidor 
en la época, el modo de pensar mítico, del cual se encuentra, sin embargo, todavía muy próximo. ${ }^{2}$

No han tardado en aparecer en la escena los que se han percatado del poder (y también de la debilidad) del nuevo instrumento del pensar humano. La gran contribución de los Sofistas parece haber sido, en efecto, el perfeccionamiento de las técnicas de argumentación racional. Pero al mismo tiempo parecen haber descubierto que esas técnicas, de por sí, no son suficientes para llevar a una decisión concluyente en favor de una tesis (o teoría), y a la consecuente supresión definitiva de las tesis rivales. Han optado, por eso, por emplear la argumentación racional no para descubrir «la verdad», sino para garantizar el éxito (momentáneo, contingente) en los debates; y han ofrecido sus servicios - así nos cuentan principalmente sus detractores- al que mejor les pagara. Sin duda hay una cierta arrogancia en su actitud, manifestada en su confianza ilimitada en el poder de sus técnicas argumentativas, capaces, según ellos, de proveer demostraciones igualmente válidas y convincentes de cualquier tesis. Pero hay, a la par, el reconocimiento implícito de la insuficiencia de tales técnicas para llegar a las teorías explicativas y unificadoras a las que aspiraban los que empezaron a desarrollar y emplear la Razón.

Contrariamente a lo que se podría tal vez esperar, la actividad crítica de los Sofistas no ha conducido al abandono del nuevo instrumento. Al contrario, sirviéndose de los mismos refinamientos introducidos por ellos, los grandes pensadores atenienses pasan a confiar más que nunca en el poder de la Razón. Creyendo haber rechazado definitivamente la crítica sofista a la Razón, pasan a emplearla para construir teorías cada vez más comprensivas, capaces no sólo de explicar la totalidad de los fenómenos, sino también de dictar normas de conducta y formas de organización social. Es el "momento de apogeo" de la filosofía griega del que hablan los historiadores, ${ }^{3}$ momento paradigmático no sólo para prácticamente toda la reflexión filosófica posterior, sino también para la constitución de la Razón Occidental.

¿Es que podemos considerar ese momento paradigmático como substancialmente arrogante? La respuesta, por supuesto, dependerá de nuestra evaluación de la relación entre lo que creen haber logrado y lo que efectivamente han logrado esos pensadores. O tal vez, más caritativamente, de un examen de las razones que tenían o podían tener para creer en el alcance de sus logros. El primer criterio es «externo»; el segundo, más bien uinterno". Ni uno ni otro son fáciles de aplicar a la obra de un Platón o de un Aristóteles, que siguen inspirándonos reverencia. Sin embargo, ambos criterios, aun aplicados con mucha cautela, indican claramente una gran exageración en la autoevaluación de sus logros por parte de tales pensadores.

Una forma de aplicar el criterio «externo» consistc en remitirse al 
«juicio de la posteridad». ¿Qué es lo que ha «quedado» de los sistemas de Platón y Aristóteles?, ¿qué es lo que, de ellos, sigue siendo "válido» después de más de dos milenios? Preguntas difíciles, que cada época y cada corriente de pensamiento ha contestado y sigue contestando en forma muy distinta. Los relativistas de índole pragmatista dirían simplemente que no puede haber una respuesta única, ya que toda respuesta depende de los fines en relación con los cuales se procede a la evaluación y del contexto en que se hace. Sin embargo, aun concediendo eso, y aun admítiendo la indudable importancia historica que han tenido esos sistemas, demostrada por su prolongada influencia y por la presencia hasta hoy día de "vestigios" de ellos en las más diversas ramas del saber, parecería que el veredicto de la posteridad es inequívocamente negativo: poco o nada en esos sistemas se considera hoy como incuestionablemente válido. Si nos atenemos nada más que a la obra de Aristóteles, buscaremos en vano un manual de ciencia que incluya alguna ley o principio o descubrimiento que lleve su nombre. Se reconoce, sin duda, su contribución a la lógica; pero sabemos que la teoría del silogismo, lejos de cubrir la totalidad de la lógica, corresponde nada más que a una pequeñisima parte de ella, parte que, además, sólo profundamente reinterpretada y reformulada ha podido integrarse en los sistemas logicos vigentes. Respecto a su metafísica, esa "filosofía primera", que ha sido base y cumbre de todo su sistema, suele reaparecer a menudo en las discusiones filosóficas, pero ¿quiénes la toman todavia en serio como expresión del conocimiento del «ser en cuanto ser»?

Para pensadores cuya labor ciertamente no ambicionaba crear monumentos o piezas de museo admirables, sino legarnos la Verdad, el severo juicio de la posteridad es tal vez crucl, pero tajante: han sido demasiado arrogantes.

Es cierto que no sc puede exigir de nadie, ni siquiera de un filósofo, que prevea el juicio de la posteridad. Pero sí se le puede exigir que sea "realista" al juzgar el valor de su propio trabajo. Es decir, que lo haga basándose en los criterios vigentes en su época y en los conocimientos de que dispone. Platón había combatido a los Sofistas, y creía - tal vez con fundamento- haberlos derrotado. Aristóteles tenía ya ante sus ojos dos siglos de evolución de la Razón Griega, incluyendo el esfuerzo de Platón por elaborar una teoría sistemática y comprensiva. Aristóteles no sólo pudo observar la rápida sucesión de doctrinas incompatibles, sino que él mismo consideró profundamente equivocada la gran teoría de su maestro. ¿Qué razones tenía o podía tener para creer que su(s) teoría(s) no tendría(n) un destino semejante al de las de sus antecesores? Podría parecer que su autoconfianza reposaba básicamente sobre dos factores. Primeramente, al igual que su maestro, creía haber llegado a un método de razonar efectivo y seguro. Su método sería superior al de su maestro 
por haber codificado en forma explícita y rigurosa sus reglas, sea en la Lógica, sea en la Dialéctica. En segundo lugar, a diferencia de su maestro, Aristóteles ve en sus teorías, en cada campo del conocimiento, una especie de destilación y cristalización del saber acumulado por sus antecesores. Su autoconfianza deriva así, en buena parte, de la confianza de la civilización griega en su superioridad - sobre todo intelectual-sobre todas las demás. Quizá sea por eso por lo que le parece natural a Aristóteles suponer que, para determinar si un principio merece o no ser incluido entre los axiomas de una rama del saber, basta con examinar y discutir lo que han pensado al respecto Tales, Anaximandro, Empédocles, Parménides y demás sabios griegos. Al fin y al cabo, fuera de ese ámbito se encuentran o bien los «bárbaros» o bien las civilizaciones que poseen un saber "meramente empírico». En ambos casos, ciertamente no ofrecen contribuciones que valga la pena considerar detenidamente. ${ }^{4}$ Aunque esa actitud esté anclada en el clima intelectual de su época, tal hecho meramente contingente difícilmente justifica la aspiración del sistema aristotélico a una validez universal e incondicional.

\section{La traición pitagórica}

¿Por qué - podría objetarse - juzgar a la Razón griega por los grandes y pretenciosos sistemas filosóficos que ha producido? ¿No sería más justo evaluar un producto más específico, pero también mucho más sólido, de esa Razón? El ejemplo que inmediatamente se ofrece son las matemáticas, de las que afirma Kant categóricamente:

Las matemáticas, desde los tiempos más remotos a que alcanza la historia de la Razón humana en la maravillosa Grecia, han seguido siempre el seguro camino de la ciencia. No se crea, empero, que haya sido para esa ciencia tan fácil [...] descubrir su real camino, o, mejor dicho, construírselo, pues me inclino a creer que por largo tiempo (particularmente entre los egipcios) fue un mero tanteo, y que el gran cambio que experimentó debe atribuirse a una revolución producida por el feliz éxito de un ensayo que algún hombre hacía, acertando con él a entrar en el camino que debía tomarse para no errar por más tiempo, y que desde ese momento quedaron abiertas y trazadas las vías seguras de la ciencia [CRP, pref. a la segunda edición, p. 66, B XI-XII].

Según la interpretación kantiana, el «feliz éxito» que revolucionó las matemáticas y las transformó definitivamente en ciencias fue el descubrir que "para conocer las propiedades de una figura, no convenía guiarse por lo que en la figura [uno] contemplaba, y menos en su simple concepto; que lo que le correspondía es señalar lo que él mismo había introducido con su pensamiento" (ibid.). Brunschvicg, siguiendo a Kant, también insiste en que la fuerza de la Razón que se descubre en las 
matemáticas es esencialmente una fuerza interna, "une puissance qui, en nous comme en autrui, se dévéloppe pour le discernement de l'erreur et de la vérité" (Brunschvicg, 1950, p. 2). Mientras Kant atribuye ese descubrimiento a la geometría griega, Brunschvicg lo atribuye más bien a la aritmética:

Cette impression salutaire d'un voile qui se déchire, d'un jour qui se lève, l'humanité d'Occident l'a ressentie, il y a quelque vingt-cinq siècles, lorsque les Pythagoriciens sont parvenus a la conscience d'une méthode capable et de gagner l'assentiment intime de l'intelligence et d'en mettre hors de conteste l'universalité [ibid.].

Tanto para Kant como para Brunschvicg, el advenimiento de las matemáticas en Grecia no se reduce a un avance en un campo específico del saber; fue más bien el paso decisivo en el desarrollo de la concepción misma de la racionalidad, paso que estableció definitivamente el paradigma de la Razón. ${ }^{5}$ Aunque las "lecturas» de ese paradigma han variado en el curso del tiempo no menos que el contenido, el ámbito y los métodos de las matcmáticas, podŕa parecer que su valor paradigmático permaneció inalterado. Se reconoce ese valor en la identificación, profundamente enraizada en Occidente, entre «razonar» y «calcular». ${ }^{6}$ Se lo reconoce también, en forma más general, en la idea de que un campo del saber o de la acción se torna "racional" si en él se aplican o imitan las matemáticas. ${ }^{7} \mathrm{Y}$ se lo reconoce en el hecho de que las crisis por las que han pasado las matemáticas - desde el "escándalo de la inconmensurabilidad" de la diagonal de un cuadrado (del que hablaremos en lo que sigue) y las dificultades con el infinito hasta las geometrías no euclidianas, las paradojas de la teoría de los conjuntos y el teorema de Gödel- hayan sido percibidas como amenazas a la propia Razón.

El rol paradigmático de las matemáticas vis-à-vis el concepto de Razón podría dar lugar a dos formas de arrogancia. Por una parte, un análisis interno de las matemáticas podría eventualmente revelar que sus pretensiones (de rigor, veracidad, etc.) son exageradas. Por otra parte, un análisis directo de sus aplicaciones e imitaciones en otros campos podría constatar que no siempre contribuyen efectivamente a la "racionalización" de esos campos. Los dos tipos de análisis me parecen proyectos importantes, pero desgraciadamente no los puedo desarrollar aquí. ${ }^{8}$ Tendré que limitarme a un ejemplo: la "traición" pitagórica.

Los pitagóricos traicionan la norma de racionalidad que habían descubierto en la aritmética al no saberse resistir "à la tentation de généraliser et de transcender les résultats de leur savoir mathématique, sacrifiant délibérément la méthode qui leur avait permis de les obtenir» (Brunschvicg, 1950, p. 3). Pasan así de la aritmética (puramente racio- 
nal) a la "aritmología» (fantástica, pueril, sobrenatural); los números dejan de ser unidades homogéneas y adquieren a sus ojos propiedades cualitativas capaces de explicar la naturaleza misma de las cosas. ${ }^{9}$ El portentoso advenimiento del homo sapiens, del matemático - dice Brunschvicg - sirve así, lamentablemente, de trampolín para el retorno triunfal del homo credulus, del acusmático (ibid., p. 4).

Si cn sus especulaciones metafísicas han pecado por "trascender y generalizar" indebidamente, en su actitud frente a la inconmensurabilidad de la diagonal con el lado de un cuadrado los pitagóricos han traicionado a la Razón en la dirección opuesta: no han osado o sabido trascender las limitaciones de su aritmética. Al ver en la imposibilidad de representar la relación entre la diagonal y cl lado del cuadrado como una proporción (ratio) entre dos números enteros una señal de irracionalidad, los pitagóricos han perdido la oportunidad histórica de «abrir un nuevo capítulo en el libro de las exploraciones y conquistas racionales" (Brunschvicg, 1950, p. 5). Han demostrado así una excesiva fidelidad a los contenidos particulares de su aritmética, sin percatarse de las posibilidades legítimas de generalización del método racional que habían descubierto.

Según ese análisis, el verdadero mérito de los pitagóricos no fue el establecimiento de ciertas verdades matemáticas, sino de la norma de lo verdadero. Para Brunschvicg, la norma, siendo interna a la Razón, no depende de variaciones (psicológicas, históricas, geográficas, lingüísticas) contingentes y externas, y por eso puede aspirar a la universalidad. En eso se opone la norma a lo que él denomina el substrato, ése sí dependiente de un fondo de hábitos mentales variables que controlan la imaginación. La tentación permanente, a la que han sucumbido Platón, Aristóteles y los pitagóricos (y no sólo ellos), ha sido la de transformar la norma en substrato. Con eso han impedido ellos el pleno desarrollo de la norma y han detenido el «élan de la raison». Si no hubiera sucumbido a esa tentación, la Razón se emanciparía del «realismo de la imaginación" y, aliando matemática y experiencia, podría "créer des combinaisons de rapports en connexion de plus en plus étroite avec les résultats de la technique expérimentale» (Brunschvicg, 1953, p. 129); lo que ocurre solamente con el "advenimiento definitivo de la ciencia racional» en el siglo XVII (ibid., p. 131).

La doble traición pitagórica llevó, por un lado, a la arrogancia y, por otro, a la falsa modestia, debidas respectivamente a que practicaron una extensión ilegítima y a que no practicaron una extensión, que hubiera sido perfectamente legítima, de las conquistas de la razón matemática. Arriesgándonos a extrapolar ilegítimamente, podemos decir que en el episodio pitagórico se revela ya el problema fundamental con que se enfrenta la Razón en toda su trayectoria posterior: ¿cómo distinguir en- 
tre aquellas de sus extensiones (aplicaciones, imitaciones, ampliaciones, etc.) que son legítimas y aquellas que no lo son? $O$, en términos más dramáticos, ¿cómo salir adelante resueltamente y sin falsa modestia a conquistar lo que le corresponde como suyo, pero sin usurpar arrogantemente lo que traspasa sus poderes y derechos? O sea, el problema que se le plantea a la Razón desde su inicio es el de conocer y aceptar su real alcance y sus límites. Su debilidad (cacaso crónica?) ha consistido o bien en no conocerlos o bien en no aceptarlos.

\section{Aislamiento}

Quizá la más frecuentemente "refutada" de las posiciones filosóficas haya sido el escepticismo. Pero su capacidad de renacer tras cada refutación únicamente es comparable a la capacidad de la Razón para sobrevivir a la crítica escéptica. El terreno en que se traba ese combate sin fin no es otro que el de la determinación de los límites legítimos del empleo de la Razón. Una estrategia de defensa muy a menudo empleada contra los ataques escépticos es la de "aislamiento», Veamos cómo se pone en práctica.

Contrariamente a lo que se suele pensar, el escéptico pirrónico no se abstiene de asentir a toda afimación de conocimiento. En un pasaje famoso de las Hipotiposis Pirrónicas, Sexto Empírico distingue entre aque$1 l o$ a que el escéptico asiente y aquello a que no asiente:

When we say that the sceptic does not dogmatize, we are not using udogmas in the more general sense in which some say it is dogma to accept anything (for the sceptic does assent to the experiences he cannot help having in virtue of this impression or that: for example, he would not say, when warmed or cooled, "I seem not to be warmed or cooled". Rather, when we say he does not dogmatize, we mean "dogma" in the sense in which some say that dogma is assent to any of the non-evident matters investigated by the sciences. For the Pyrrhonian assents to nothing that is non-evident. ${ }^{10}$

Podría parecer natural interpretar este texto identificando aquello que es "no-evidente» con lo que se puede conocer sólo inferencialmente, es decir, con aquello que requiere alguna labor «teórica» para ser «descubierto». La «naturaleza de las cosas», por ejemplo, pertenece a esa categoría, y por eso cualquier tesis referente a ella no puede ser objeto del asentimiento del escéptico. Gassendi expresa ese punto de vista cuando escribe:

[...] it is impossible for us to know, i.e. [...] to affirm surely and infallibly that something is by nature and in itself, and as a result of basic, necessary and infallible causes, constituted in a certain way $[. . .]^{11}$ 
Según esa interpretación, el escéptico se opone a juicios teóricos; precisamente los juicios que la Razón griega se vanagloriaba de haber podido establecer. Pero esa oposición en nada afecta a la experiencia común, cuyos juicios presumiblemente «evidentes» no hay por qué poner en duda. Aun si no puedo saber cuál es la naturaleza del tiempo, puedo seguir planeando mis vacaciones del próximo verano. El escepticismo tendría entonces un ámbito restricto, y su daño se circunscribiría así a un dominio muy lejano de la vida común, el dominio de la filosofía $o$ de la ciencia.

Es esa estrategia de interpretación del escepticismo clásico a la que Burnyeat (1984) llama - muy apropiadamente - de "aislamiento». De manera bastante convincente el demuestra que, aunque esa estrategia prevaleció a partir del siglo XVI, no es compatible con los textos. Sexto, según Burnyeat, no separa en la forma sugerida el dominio teórico y la vida común, y claramente considera su escepticismo como directamente pertinente para la conducta cotidiana. Los detalles de la demostración de Burnyeat no nos tienen que ocupar, aquí, pues lo que nos interesa es ver cómo funciona la estrategia por él identificada.

El aislamiento desplaza el debate de un nivel o dominio hacia otro: ya no todos los juicios son afectados por el escepticismo, sino solamente los juicios teóricos; ya no todos los dominios de la vida, sino solamente la construcción de teorías. Con ese paso, se crea una «zona de seguridad" privilegiada, declarada fuera del alcance de una determinada forma de crítica. Al mismo tiempo, se puede ser "generoson, aceptando esa crítica como válida, siempre que se aplique a un ámbito circunscrito. Si en un primer momento se protegió por medio de esa estrategia la "vida común", más adelante la misma estrategia ha servido para legitimar ciertas formas de teorización, mientras se rechazaba otras. Es el caso del mismo Gassendi que, en su fase de "escéptico constructivo», pasố a restringir aún más el alcance de los argumentos escépticos, considerándolos válidos contra la ciencia especulativa o la especulación metafísica, pero no contra toda forma de teorización sobre lo "no-evidente». ${ }^{12}$ Es esa la maniobra que permite alabar a Gassendi como héroe de la Razón Moderna, como quien uaccomplished one of the more important revolutions of modern times, the separation [i.e. aislamiento, M.D.] of science from metaphysics» (Popkin, 1979, p. 145).

Gracias a la estrategia de aislamiento, la Razón puede sobreponerse al escepticismo, reorientando sus esfuerzos hacia mctas inicialmente más «modestas». Ya no se trata de captar la naturaleza íntima de las cosas o su razón última, sino "meramente" de dar cuenta de cómo se interrelacionan (de preferencia en términos de leyes cuantitativas). En la ausencia de técnicas experimentales suficientemente precisas para determinar la velocidad de la luz, Galileo «modestamente» profesa la suspen- 
sión del juicio al respecto; Newton se abstiene de "hacer hipótesis» sobre la posible existencia de un plan divino según el cual se habrían creado el sistema solar y las fuerzas de la naturaleza, "contentándose» con describirlas con precisión. Pero, modestia aparte, ambos confían absolutamente en haber descubierto los verdaderos principios que rigen la naturaleza y el verdadero método para conocerlos. Basta recordar lo que escribe Newton en el prefacio de los Principia:

Ofrezco esta obra en calidad de principios matemáticos de la filosofía, porque la tarea entera de la filosofia parece consistir en esto: partir de los fenómenos de los movimientos para investigar las fuerzas de la Naturaleza y, entonces, partir de esas fuerzas para demostrar los otros fenómenos [...]; deseo que el resto de los fenómenos de la Naturaleza se pueda derivar de los principios mecánicos por un razonamiento de la misma especie, porque he sido inducido por muchas razones a sospechar que todos ellos dependen de ciertas fuerzas que hacen que las partículas de los cuerpos, por algunas causas desconocidas hasta ahora, o se atraen mutuamente y se unen en figuras regulares, o bien se repelen y se alejan unas de las otras. Como estas fuerzas se desconocen, hasta ahora los filosofos han intentado en vano explorar la Naturaleza; pero yo espero que los principios aquí establccidos puedan arrojar alguna luz sobre csto o acerca de un método más verdadero para la filosofia. ${ }^{13}$

Protegida del escepticismo por una hábil maniobra de aislamiento, la Razón recobra su autoconfianza, y desde su nueva posición atrincherada parte así para nuevas expediciones arrogantes. No hay que esperar a un Laplace - quien cree que los adelantos de la ciencia nos acercan a aquella inteligencia superior capaz de reunir en una única fórmula los movimientos de los mayores cuerpos y de los menores átomos, permitiéndole, dadas sus posiciones en cualquier instante, tener ante sus ojos todo cl pasado y el futuro del universo- para observar cse nucvo estado de espíritu. Ya antes del apogeo newtoniano, Galileo creia haber descifrado el «código» de la naturaleza, Descartes confiaba en la «luz natural» de la Razón, Leibniz formulaba un método «mecánico» capaz de constituirse en juez absoluto de toda controversia y Perrault, expresando sin duda la opinión corriente, afirmaba, en 1668, que se había logrado "un progreso prodigioso en las artes y las ciencias en los últimos cincuenta o sesenta años». ${ }^{14}$ La Razón Moderna -como la Razón griega- nace ya decididamente arrogante.

La legitimidad aparentemente incontestable de la estrategia de aislamiento puede provenir de su eventual relación con uno de los lances típicos de la antigua práctica de la disputatio. En esa práctica, al enfrentarse con un contraargumento, el proponente de una tesis tiene la opción (legítima) de defenderse diciendo "Distingo!», es decir, restringiendo el impacto del contraargumento a un sentido o aspecto (casi siempre 
trivial) de su tesis. ${ }^{15}$ Sea cual sea su origen, el difundido empleo del aislamiento se debe sin duda a que es mucho más eficaz que el contraataque frontal, como el que han practicado Descartes o G.E. Moore. El primero, al tratar de combatir a los escépticos en el terreno y con las armas de ellos, acaba o bien por "contaminarse" de escepticismo, tornándose un "sceptique malgré lui», o bien por atrincherarse en un dogmatismo incapaz de sobrevivir a los mismos argumentos escépticos que él creía haber desechado (cfr. Popkin, 1979, pp. 193-213; Stroud, 1984, pp. 37-38, 140-141, 255). El segundo, al rehusar admitir que los argumentos escépticos afecten en lo más mínimo a las creencias más ordinarias, se presta fácilmente a la acusación de no haber siquiera comprendido o de no querer admitir el verdadero alcance de esos argumentos (cfr. Wittgenstein, 1969, § 19 y $\S 24$ ). La defensa directa de la Razón resulta así ser demasiado frágil, pues trata desesperadamente de mantener en su poder un terreno ya minado por el escepticismo. Tal no ocurre, sin embargo, con la defensa indirecta típica de la estrategia de aislamiento: se preserva la fuerza de la Razón haciéndola retroceder (o elevarse) a un área o nivel privilegiado, todavía no afectado por las críticas escépticas, y supuestamente inmune a ellas.

Es atacando la posibilidad misma de crear tales refugios como los críticos "posmodernos" de la Razón Moderna han tratado de suprimir las bases sobre las que reposa la estrategia de aislamiento. De ahí su afán de extinguir las distinciones entre cuestiones «internas" y «externas", entre "framework" y "content", entre "analítico" y "sintético", entre "narrativa» $\mathrm{y}$ «metanarrativa", entre "nivel objeto" $\mathrm{y}$ "metanivel», entre «texto» y urealidad" y otras semejantes. Si tienen éxito, el discurso o la realidad se transforman en una inmensa llanura, donde la Razón no encontrará ya atrincheramientos posibles. He analizado ese tipo de crítica en otra parte (cfr. Dascal, 1988a, pp. 11-19 y 24-28). Aquí, quisiera enfocar algunos tipos importantes de aislamiento y los problemas más bien «internos» con que se enfrentan, tratando de ver si, luego de un primer momento de modestia y autoconfinamiento que le restaura la seguridad amenazada, no tiende sicmpre la Razón a volverse arrogante de nuevo, rebasando sus autoimpuestos límites.

\section{Departamentalización}

Una forma directa y aparentemente sencilla de impedir la arrogancia de la Razón es confinarla a ciertos dominios bien delimitados, como las matemáticas, las ciencias naturales o la tecnología. En eso, los esfuerzos de críticos y defensores de la Razón a veces coinciden. Ambos pueden admitir, por ejemplo, que la teología revelada está fuera del alcance de la inteligibilidad racional y que sus dictámenes tienen que ser seguidos por 
un acto de fe no susceptible de justificación racional. La Razón, por otra parte, es soberana en su propia esfera de actuación, es decir, allí donde la revelación y la fe nada tienen que decir. Otro ejemplo de convergencia entre partidarios y críticos de la Razón es la aceptación de la dicotomía valores/hechos, y la restricción del ámbito de la Razón a su segundo miembro.

Aunque haya coincidencia, los motivos para la aceptación de esas u otras limitaciones son generalmente opuestos. Mientras los primeros creen proteger así del «imperialismo" de la Razón áreas como la teología, los fenómenos humanos o la ética, los otros aceptan la delimitación para proteger más bien a la Razón ante aventuras especulativas que podrían debilitarla. Cuando Pascal nos dice que «le coeur a des raisons que la raison méconnaît», quizá sugiere que hay un sector de nuestra experiencia al que tenemos acceso directo, no mediado por la Razón, y que no por eso es menos fundamental y válido. Pero cuando los neopositivistas interpretan las afirmaciones éticas, estéticas y religiosas como teniendo un "significado emotivo», o cuando comparan la metafísica a la poesía, lo que les interesa no es reconocer la validez de otros modos de conocer, sino más bien "mantener la consistencia general de [su] posición", como lo confiesa Ayer (1946, p. 20). O sea, se trata para ellos de mantener el "principio de verificación» como criterio exclusivo de significación (literal). Oraciones o juicios que no se conforman a ese criterio - es decir, que no son o bien analíticos o bien empíricamente verificables- son declarados desprovistos de significado literal, y así dejan de ser candidatos a los títulos "verdadero o falso", "científico" y, por ende, «racional». Se reconoce así que la Razón no necesariamente se aplica a todos los dominios, y se ve en eso una actitud benéfica para la salud de la propia Razón. Sea cual sea la motivación, sin embargo, el hecho es que se admite -implícita o explícitamente- la posibilidad de coexistencia entre el «juego de lenguaje» racional y otros juegos, regidos por otras reglas.

Pero esos confinamientos interna o externamente impuestos a la Razón pronto parecen arbitrarios. Así como la fe en un ser todopoderoso no se conforma fácilmente con restringir su alcance, la Razón no renuncia a lo que considera ser su derecho de expandirse ilimitadamente. ¿Por qué no reproducir, en otros dominios, los éxitos que ha obtenido en algunos campos privilegiados? El afán de "racionalizar» (en el sentido de Weber) los demás «departamentos» de la actividad humana es difícil de contener. De la misma manera que el capitalismo, ignorando el Muro de Berlín o la Muralla China, acaba por suprimir las barreras nacionales y convertir el planeta en un único "world-system» al que se subordinan todos los sistemas económicos, también la Razón, por su éxito mismo, amplía cada vez más su espacio de actuación. Uno puede ver en ese 
proceso una lamentable "colonización" de la Lebenswelt por el System con el consecuente peligro de desaparición de dimensiones importantes de la vida humana (Habermas). Uno puede denunciarlo como cxpansión ilegítima de un modo de conocer "teórico" (opuesto a la Zuhandenheit o praxis), que gradualmente monopoliza la verdad, llevando a una situación en que el hombre ya no puede reconocer su propio Ser: «Indessen begegnet der Mensch heute in Wahrheit gerade nirgends mehr sich selber, d.h. seinem Wesen» (Heidegger, 1962, p. 27). Pero la vehemencia misma de esas denuncias y lamentos revela la fuerza y quizá la irreversibilidad del proceso de expansión arrogante de una Razón que rchúsa permanecer encerrada en un departamento, por más confortable y seguro que sea.

\section{De profundis}

La expansión de su esfera de actuación acarrea un problema serio para la Razón: la diversidad. Una de las fuentes de su orgullo y también de su legitimación es su supuesta capacidad de ofrecer explicaciones uniformes basadas en principios universales. Pero, al tratar de cubrir una variedad cada vez más amplia de fenómenos y ramas del saber, corre el riesgo de no poder ya concretar esa promesa. Por otra parte, aceptar la irreductibilidad de la diversidad sería una traición mayor, pues equivaldría a confesar su fragmentación en una multiplicidad de "razones", posiblemente "inconmensurables» entre sí, es decir, no armonizables «racionalmente». La superación de ese obstáculo exige otra estrategia de aislamiento: la profundización. Se trata de buscar la unidad de lo diverso en capas cada vez más "profundas». La expansión horizontal de la Razón requiere así de su expansión vertical.

El "orgullo profundo" más conocido - y criticado- de la Razón es quizá la búsqueda cartesiana del fundamento único sobre el que reposa todo el edificio de la ciencia. Pero la misma preocupación se manifiesta también en cada habitación de ese edificio. Tomemos, por ejemplo, la lingüística. Frente a la diversidad sintáctica de las lenguas, la Gramática de Port Royal postula un substrato lógico común, del que la diversidad nada más es que la manifestación "superficial». Frente a la heterogeneidad desconcertante de la "parole», Saussure define la «langue» como un objeto homogéneo, concebido como puro sistema de relaciones, y estipula que es a ese objeto "profundo", inmune a las variaciones del comportamiento lingüístico real, al que tiene que volcar su atención la investigación lingüística. Chomsky, al tratar de combinar las contribuciones de Arnauld y Saussure en una sola teoría, nos lleva a capas aún más profundas: cada "langue» es un conjunto de reglas cuya posesión por cada hablante constituye una "capacidad de primer orden" subyacente a su 
comportamiento lingüístico; además, cada infante humano posee una "capacidad de segundo orden» que le permite aprender cualquier lengua a que sea expuesto. Es esta profundísima capacidad de adquirir capacidades la que, para Chomsky, es el verdadero objeto de la lingüística, el que le confiere su "poder explicativo" y unificatorio.

Apelar a esa capacidad de segundo orden es necesario, según Chomsky, porque de otra forma sería imposible dar cuenta del aprendizaje de una lengua. Si el infante tuviera a su disposición nada más que los pocos y fragmentarios ejemplos de comportamiento lingǘrstico de los individuos que lo circundan, no podría jamás construir a partir de ellos el complejo sistema de reglas que se manifiesta en su propio comportamiento lingüístico ulterior. Se le tiene que atribuir, por lo tanto, la posesión previa de una capacidad que le indica de antemano cómo construir esos sistemas. Esa capacidad establece un espacio de sistemas (o lenguas) posibles, que difieren solamente en los valores que toman ciertos "parámetros». El aprendizaje o adquisición de una lengua consiste en «ajustar» esos parámetros, es decir, seleccionar sus valores de acuerdo a los datos proveídos por el entorno lingüístico específico en que se encuentra el niño.

Ese procedimiento permite, sin duda, "conquistar la diversidad", reduciéndola a algo relativamente marginal o «superficial». Pero eso sólo es posible gracias a que ella ha sido previamente restricta a un espacio de variación posible rigurosamente determinado. A los ojos de Chomsky, esa imposición de límites a la diversidad es justificada por ser la condición misma para el ejercicio de la racionalidad. «Si no se comenzara sabiendo que solamente determinadas cosas son teorías posibles -dice Chomsky en un debate con Foucault-- no sería posible ninguna inducción. Partiendo de los datos se podría ir a cualquier lugar, en cualquier dirección" (Chomsky y Foucault, 1976, p. 36). La actividad científica, por lo tanto, no puede contentarse con "tratar con los fenómenos y su interrelación directamente y nada más» (ibíd., p. 46). Si queremos hacer ciencia, es decir, ejercer nuestra Razón, tenemos que admitir la existencia de un «conjunto de principios [...] que define para nosotros lo que es una estructura intelectual posible, $o$, si usted quiere, una posible ciencia profundas (ibid., p. 48).

A la vez que el objeto privilegiado de su actividad se hace más recóndito, la Razón se vuelve más eficazmente protegida ante la diversidad. En el espacio de las «estructuras intelectuales posibles», ella es, de hecho, soberana. No sorprende que defienda con uñas y dientes la invariancia de la estructuras subyacentes o de los principios que cree haber descubierto. Chomsky no duda en declarar innata la "capacidad de segundo orden" o, lo que da lo mismo, tomarla como definitoria de (parte de) la «naturaleza humana». Konrad, Lorenz no duda en postular la 
existencia de una "función de supervivencia", aun si no ha sido descubicrta, para toda estructura o comportamiento biológicos, con lo que convierte la hipótesis de Darwin en un axioma. ${ }^{16}$ La tarea de conectar lo profundo e invariante con lo superficial y diverso es dejada para mecanismos transformacionales, suficientemente poderosos como para ser capaces de interpretar la diversidad mostrando cómo puede siempre traducirse a un vocabulario unitario y profundo predeterminado.

La creencia en ese vocabulario último al que convergen todas las transformaciones equivale a la creencia en estructuras que poseen un "centro" que las comanda pero que, por su posición privilegiada misma, «escapa a la estructuralidad" (Derrida, 1967, p. 410). No se trata de confiar en que el vocabulario profundo propuesto por uno es absolutamente definitivo en el sentido de constituirse en punto final de la reducción de la diversidad. Chomsky admite la posibilidad de una explicación de las capacidades mentales innatas en términos neurofisiológicos o biológicos. Malinowski (1969, p. 159), aunque operando con la noción básica de función cultural, está convencido de su reductibilidad a la de necesidad biológica. Lévi-Strauss, después de haber mostrado cómo una «humanité générale" subyace a las diferencias de las "humanités particulières", habla de la futura tarea de "réintégrer la culture dans la nature, et finalement, la vie dans l'ensemble de ses conditions physico-chimiques» (1962, p. 327). Pero sí se trata de creer que hay algún vocabulario privilegiado en el que termina toda la actividad de traducción o interpretación, de creer en un ujeu fonde, constitué depuis une immobilité fondatrice et une certitude rassurante, elle-même soustraite au jeun (Derrida, 1967, p. 410.)

Sin embargo, como lo señala Derrida, hay otro concepto posible de estructura en que nada "escapa a la estructuralidad»: el de una estructura sin centro, de un juego tout court, sin fundamento y sin seguridad. ${ }^{17}$ Cuando Foucault, en el mismo debate ya mencionado, dice que "desconfíla un poco de la noción de naturaleza humana" (Chomsky y Foucault, 1976, p. 15), negándole el estatuto de un "concepto científico» y atribuyéndole el rol de eindicador epistemológico para designar ciertos tipos de discurso en relación con la teología, la biología o la historia, o bien en oposición a éstas» (ibid., p. 17), está de hecho negándole la posibilidad de funcionar como punto de apoyo para todo el sistema chomskyano. Y cuando, más adelante, insiste en su interés por un estudio de las solas transformaciones del conocimiento, «sin pasar por un "inventor" original que descubra la "verdad" " (ibíd., p. 29), ${ }^{18}$ es hacia un juego de transformaciones $\sin$ "centro" - sin inicio, sin fin y sin dirección definidos- hacia donde apunta. La única regla de este juego es que no hay nada fijo, que todo es susceptible de transformación. Es un juego en que, de hecho, no hay más que transformaciones que remiten las unas a 
las otras; en que todo está en un mismo plano; y en que la profundidad no es más que una ilusión. A lo mejor no es ése el juego de la realidad o de la historia, pero, si lo es (y ¿quién lo puede saber si no es presuponiendo un conocimiento "profundo» de la realidad o de la historia?), la creencia en una "ciencia profunda» es gratuita: quizá no tanto un ejemplo de arrogancia como de ingenuidad de la Razón.

\section{Trascendentalización}

Se podría decir que las dificultades enfrentadas por las estrategias de protección de la Razón que hemos examinado resultan de su carácter «territorial». Atribuírle a la Razón un territorio definido - sea horizontal, sea vertical, y sea cual sea su extensión- es, en los términos de Brunschvicg, ceder a la tentación de subestratificarla. Pero, al proceder de csa forma, inevitablemente se anula la distancia entre la Razón y sus productos, haciéndola vulnerable a las críticas dirigidas hacia ellos. Lo que hay que tratar de hacer, si se quiere asegurar una posición inexpugnable a la Razón, es definirla no de manera "geográfica», sino en orden a situarla no "arriba", "abajo» o "por detrás" de sus productos, sino "fuera" de ellos. Sólo así podrá la Razón, al mismo tiempo que de algún modo sostiene sus productos, ponerse fuera del alcance de la contingencia que inevitablemente los torna perecederos. Es esta la línea de acción que adoptan las estrategias de aislamiento que paso a examinar en esta sección y la próxima.

La estrategia de trascendentalización que quiero discutir aquí no es la que postula la existencia de objetos, fuerzas o poderes «trascendentes». Pues, si esas entidades son extrarracionales, tal estrategia en nada ayuda a la defensa de la Razón; si, por otra parte, son racionales, siendo "entidades», la estrategia se reduce a las versiones «territoriales» ya analizadas. Es más bien la versión kantiana de la trascendentalización la que aporta algo nuevo a nuestra discusión. No tengo la posibilidad de discutirla en produndidad aquí. Me limitaré a recordar su caracter aislatorio y a señalar algunos problemas a este respecto.

De las muchas maneras posibles de describir el aporte de Kant, quizá la más pertinente para nuestros propósitos sea la siguiente. Al contrario de los que se enfrentan al escepticismo tratando de demostrar - contra ellos - que el conocimiento es posible, Kant toma la existencia del conocimiento como su punto de partida, y trata de demostrar cómo es posible. El conocimiento que le sirve de punto de partida es el conocimiento "empírico», sea el de las ciencias, sea el del hombre común. Ese conocimiento - p. e., de los objetos que nos rodean- es obtenido por medio de la «experiencia». La tesis principal de Kant es que nociones como las de "objeto», «espacio», «tiempo», etc., que son indispensables 
para que podamos tener cualquier «experiencia», provienen de la mente cognoscitiva y no "de fuera». Al conocimiento de esa contribución de la mente a la constitución de la experiencia y del conocimiento empírico, él lo llama conocimiento trascendental. El conocimiento trascendental tiene que ser de otro tipo porque, si fuera también "empírico", sería un conocimiento de objetos de la experiencia, como lo es todo conocimiento empírico, y no de sus condiciones de posibilidad. Además, si fuera empírico, no sería conocimiento de algo que es necesario para toda experiencia, pues ningún conocimiento empírico es "necesario». En este breve resumen, se ven ya los pasos esenciales con que Kant garantiza la eficacia aislatoria de la trascendentalización. Algunas citas más completarán el cuadro:

"Llamo trascendental a todo conocimiento que en general se ocupe, no de los objetos, sino de la mancra que tencmos de conocerlos, en tanto que sea posible a prioris (CRP, pp. 84-85, B 25). La Razón (Vernunft) es «la facultad que proporciona los principios del conocimiento a priori» (CRP, p. 84, B 25). Siendo así, el conocimiento trascendental es el conocimiento a priori que tenemos de la Razón. Pero, como el conocimiento trascendental no es un conocimiento de cobjetos", la Razón tampoco puede ser un «objeto». ¿Cómo podría serlo aquello que es condición de posibilidad para pensar o percibir «objetos»? Tampoco las demás nociones que caracterizan toda experiencia empírica pueden aplicarse a la Razón. Ella no ocupa una posición en el espacio o en el tiempo, no tiene sustancia, cantidad, etc. Está definitivamente "fuera" de todo eso. Para enfatizar aún más el carácter no-empírico del conocimiento trascendental y de la Razón que él permite conocer (y proteger), Kant define la Razón pura como la que «contiene los principios para conocer algo $a b$ solutamente a prioris (ibid.), conocimiento ése que es absolutamente puro, es decir, «no contiene nada empírico o sensible, y, por lo tanto, es completamente posible a priori” (ibid., A 11). La Critica de la Razón Pura es (la parte propedéutica de) la ciencia que se ocupa de ese tipo de conocimiento.

El trascendentalismo kantiano ha sido criticado de varias maneras. ${ }^{19}$ Pero quiero atenerme a las críticas pertinentes para evaluar su eficacia aislatoria. Burnyeat muestra que el lance de que se sirve Kant para refutar al escepticismo es típicamente aislatorio: la separación entre el nivel empírico y el nivel trascendental le permite reinterpretar la tesis «idealista" escéptica (todo lo que percibimos depende de nosotros para su existencia) de manera que no impugne la objetividad del conocimiento, es decir, el "realismo» (existen objetos independientes de nosotros, que percibimos directamente); la primera es verdadera entendida "trascendentalmente», y la segunda, entendida «empíricamente»; gracias a esa separación, por lo tanto, Kant puede ser, a la vez, un wrealista empírico" y 
un «idealista trascendental». De esta forma - prosigue Burnyeat- Kant creyó haber refutado definitivamente el escepticismo, pero el efecto ha sido que el escepticismo también ha pasado al nivel trascendental, cuestionando ya no directamente el conocimiento empírico, sino la posibilidad de un conocimiento trascendental, necesario según Kant, para justificar el primero (Burnyeat, 1984, p. 250). Stroud, por otra parte, ha argumentado que, independientemente do lo que haga el escéptico, hay problemas serios con el concepto de un conocimiento trascendental, internos al sistcma de Kant. Por una parte, ese concepto envuelve una cierta circularidad. ${ }^{20}$ Por otra, una imposibilidad: el pensamiento humano sólo es posible, según Kant, gracias a la aplicación de las categorías; pero éstas se aplican solamente dentro de los límites de la experiencia posible; dicho de otro modo, la "aplicación" de las categorías es siempre "empírica"; ¿cómo entonces, pregunta Stroud (1984, p. 161), "could there be intelligible thought and discourse in terms whose employment is not determined by empirically ascertainable conditions we can discover to hold in our experiencen?

Creo que se podría "completar» el argumento de Stroud agregando que, una vez establecida la separación estricta de los niveles trascendental y empírico, no sólo el conocimiento trascendental se revela vacío de contenido, sino también se muestra incapaz de cumplir su función esencial, la de explicar la posibilidad del conocimiento empírico. Recuérdese que esa explicación no puede simplemente consistir en mostrar que las categorias del entendimiento puro son necesarias para que tengamos el concepto de experiencia (que es lo que prueba la Deducción Trascendental). Hay que mostrar también cómo la experiencia es posible, es decir, cómo las categorías se pueden aplicar a los datos sensoriales. Según Kant, un concepto tiene aplicación cuando es "homogéneo" con los datos a los que se aplica. Un concepto empírico, perteneciendo al orden de la experiencia, no tiene problema en ser considerado "homogéneo" a sus datos y, por lo tanto, aplicable. Pero un concepto puro del entendimiento - como lo son las categorías- es radicalmente heterogéneo con lo sensible. Si es así, ¿cómo puede aplicarse a él? ${ }^{21}$ Como se sabe, la solución kantiana para ese problema crucial es crear un «intermediario», llamado "esquema trascendental», que tiene, por así decir, un pie en lo trascendental (siendo así «homogéneo» con las categorías) y otro en lo sensible (siendo así "homogéneo" con los datos de la experiencia). Pero las pocas páginas de la Crítica de la Razón Pura dedicadas a esta doctrina del esquematismo están muy lejos de aclarar la naturaleza de esa entidad problemática y la forma en que ejecuta su tarea de colmar el abismo que separa lo trascendental de lo empírico, como lo han señalado muchos comentadores. ${ }^{22} \mathrm{Si}$-como hay fuertes razones para creer- la doctrina del esquematismo falla en su misión, el resultado del trascendentalismo 
radical de Kant es un aislamiento total -y por eso mismo estéril- de la Razón; y su pretensión de explicar y fundamentar todo nuestro conocimiento se revela como un ejemplo más de la arrogancia de la Razón.

\section{El recurso del método}

El afán de descubrir el método de descubrimiento ha acompañado cada descubrimiento de la Razón. Raros son los pensadores que se han contentado con producir "resultados". La gran mayoría ha tratado de reflexionar también sobre la manera como los ha producido. Y muchos han creído posible formular preceptos generales para producir más resultados del mismo tipo. Desde el órganon aristotélico hasta el abortado «general problem solver» y la teoría bayesiana de la decisión, la historia de las ideas ha visto una sucesión interminable de propuestas de preceptos metódicos que garantizarian, seguidos estrictamente, si no el hallazgo de soluciones racionales para cualquier problema que se le plantee al hombre, por lo menos la posibilidad de seleccionar racionalmente, entre las soluciones propuestas, la más adecuada.

Naturalmente, la tendencia de esos pensadores ha sido la de tomar el método como núcleo de la racionalidad, núcleo del que ella irradiaría, por una parte, a los productos de su aplicación y, por otra, a las facultades necesarias para aplicarlo y a los seres que lo aplican. Ya hemos visto cómo Brunschvicg, siguiendo esta línea de pensamiento, identifica Razón y «norma». Más recientemente, Jesús Mosterín afirma que «la racionalidad - en el significado en que aquí la entendemos- no es una facultad, sino un métodon (1987, p. 17).

Mi propósito aquí no es cuestionar la conocida nómina de ventajas que la posesión de un método seguro para conocer y actuar traería al género humano. ${ }^{23}$ Tampoco nos tiene que ocupar el natural orgullo (a la luz de la sucesión histórica de métodos diferentes, obviamente injustificado, y por lo tanto arrogante) que han sentido los que creyeron haber descubierto el verdadero método. Finalmente, no se trata de investigar, $a$ la Weber, los cambios sociales que llevaron a la transformación de la Razón en método, o de lamentar, como él, el «desencantamiento» que esa reducción de la Razón a la instrumentalidad (Zweckrationalität) produce en nuestras vidas. ${ }^{24}$ Lo que nos interesa aquí es mostrar cómo la reducción de la racionalidad a un método sirve como estrategia defensiva a la Razón frente a sus críticos, y examinar algunas consecuencias de esa estrategia. Para eso veamos inicialmente cómo elabora Mosterín su tesis.

El punto de partida de Mosterín - como el de la inmensa mayoría de las teorias contemporáneas de la racionalidad - es una admisión sincera de modestia: en virtud de la falibilidad de todas nuestras creencias, la racionalidad en cuanto método no puede pretender garantizar la certi- 
dumbre que prometían Descartes y otros. Pero sí promete, sea en su versión "creencial" (referente a nuestras creencias u opiniones), sea en su versión "práctica» (referente a nuestras decisiones y acciones), la «maximización de nuestros aciertos y minimización de nuestros errores a largo plazon (Mosterín, 1987, p. 20). ¿Oué es lo que tenemos que hacer para garantizar, a la larga, esa convergencia hacia la verdad y hacia la consecución de nuestros fines últimos? Tenemos que maximizar los aciertos y minimizar los errores de cada una de nuestras elecciones particulares, de creencias o de líneas de conducta. Es decir, aun si no garantiza la verdad de una creencia específica que elegimos o la eficacia absoluta de una cierta línea de acción por la que nos decidimos, la racionalidad consiste en la exigencia de que cada una de nuestras elecciones y decisiones sea la mejor posible bajo unas circunstancias dadas. ${ }^{25}$

Restringiéndonos al caso de la racionalidad creencial, esa exigencia se traduce, para Mosterín, en una exigencia de justificación. Una creencia es racional si es justificada, y es justificada si es: o bien analítica, o bien evidente (o directamente observada), o bien aceptada por la comunidad científica pertinente, o bien basada en testimonios fiables, o bien lógicamente derivable de otras creencias justificadas. Además, no puede estar en contradicción con otras creencias justificadas, ya que un sistema de creencias racionales tiene que ser lógicamente consistente. En caso de conflicto de creencias o de modos de justificación (o impugnación) de una creencia dada, alguna jerarquía implícita o explícita tiene que ser admitida, para que sepamos qué creencias es racional retener o rechazar. Pareciera, por el orden en que presenta los modos de justificaciôn, que Mosterín asume que la analiticidad y la evidencia observacional tienen más peso que, digamos, la fiabilidad de los testimonios, en casos de conflicto.

En ese modelo, la racionalidad de una creencia no es una propiedad intrínseca de la creencia, sino que deriva del método empleado para justificarla o defenderla. Igualmente derivada es la racionalidad de un individuo, que consiste en su disposición a aceptar todas y sólo las creencias racionales. Si acepta más creencias que las que racionalmente puede creer, es un dogmático; si acepta menos, es un escéptico (Mosterín, 1987, p. 23). Para no caer en el dogmatismo (o en el escepticismo), un individuo racional tiene que estar atento a los cambios que pueden darse en la justificación de las creencias, debidos a nuevos descubrimientos científicos, a la posible invalidación de testimonios u obscrvacioncs, y - ipor qué no?- a modificaciones en el status analítico o sintético de ciertas proposiciones, Esa atención permanente corresponde a la adopción de lo que Mosterín denomina uel talante crítico»: «Desde un punto de vista racional todo puede - y todo debe- ser puesto en cuestión» (p. 37).

«Poner todo en cuestión» es una máxima típicamente escéptica. 
¿Cómo ponerla en práctíca sin caer en el escepticismo? La investigación escéptica (zétesis) efectivamente tiene por objetivo refutar toda tesis propuesta (cfr. Olaso, 1988), con el fin de llegar al equilibrio de las opiniones (isosthéneia) que, a su vez, lleva a la suspensión de juicio (epoché) y finalmente a la tranquilidad (ataraxía). El hombre racional de Mosterín, al contrario, no cree que las razones en pro y en contra de una tesis estén, a largo o a corto plazo, en equilibrio. Él cree, más bien, en la maximización, es decir, en la posibilidad de encontrar razones favorables a una tesis y desfavorables a sus rivales, de modo que permita una elección racionalmente motivada entre ellas. Su talante crítico pretende demoler ciertas tesis, es cierto, pero con el fin de reemplazarlas por otras mejores. Y su investigación consiste esencialmente en el ejercicio de un cálculo de los valores que maximizan lo que la teoría de la decisión llama "funciones de utilidad". Ahora bien, ese cálculo sólo es posible cuando los parámetros de esas funciones han sido fijados, por lo menos provisoriamente. Si no podemos atribuir, por ejemplo, probabilidades a las ocurrencias de los resultados de conductas alternativas, nos falta un dato esencial para elegir racionalmente la más deseable; igualmente, la posibilidad del cálculo depende de la fijación de un conjunto de alternativas a comparar, de una lista de factores considerados pertinentes, de un orden de preferencias o valoraciones, etc. Sin duda, todo eso puede ser ulteriormente puesto en cuestión y quizá a largo plazo efectivamente venga a serlo. Pero cada acto particular de ejercicio de la racionalidad maximizadora no sólo no pone «todo» en cuestión, sino, al contrario, atrinchera o fija «casi todo".

$\mathrm{El}$ hombre racional mosteriniano tiene una vida difícil. Si efectivamente pone todo en cuestión a cada momento, no puede ya maximizar, y se vuelve escéptico. $\mathrm{Si}$, por otra parte, acostumbrándose a no poner en cuestión ciertas cosas al ejercer el cálculo de la maximización, las deja atrincherarse cada vez más en su praxis investigativa, se porta como un dogmático. El "talante crítico" le recuerda que no debe actuar así, pues aunque de facto no cuestione muchas cosas, nada es de iure incuestionable. Pero muchas veces lo que ocurre de facto acaba por adquirir también una legitimación de iure. En particular, creo yo, la concepción misma del método en cuanto núcleo de la racionalidad tiende a atrincherarse de tal forma que se torna virtualmente incuestionable, pese a las declaraciones en contrario de Mosterín y muchos otros. ${ }^{26}$ Veamos brevemente cómo eso suele pasar.

La noción de maximización es bastante precisa. El máximo -en el caso de una función «bien comportada»- es un punto definido, matemáticamente determinable. Pero es una noción de difícil aplicación, especialmente para explicar la acción y las creencias humanas. Una de las dificultades está en el hecho de que, para tomar una decisión racional, necesita- 
mos información; esa información tiene que ser obtenida o reunida de alguna forma; pero obtener información tiene un "precios (cuesta tiempo, esfuerzo, etc.); si invertimos demasiado o insuficiente esfuerzo en la obtención de la información, ponemos en riesgo lá racionalidad de nuestra decisión (podemos perder la oportunidad de decidir, o dejar de considerar datos pertinentes); lo idealmente racional sería maximizar previamente la "función de utilidad" de la información, para determinar precisamente su precio o valor relativo a nuestro propósito inicial; pero para eso necesitaríamos más información, y nos meteríamos así en una regresión infinita. Lo que hacemos de hecho es renunciar, en algún momento, a la estrategia de maximización y contentarnos con una decisión «intuitiva", que suponemos "razonable" o "satisfactoria" respecto a la recogida de información. ${ }^{27}$ Pero nociones como «intuición», "razonable» y "satisfactorio" son esencialmente vagas. Al admitir que tenemos que basar el ejercicio de la maximización en ellas, reconocemos el hecho de que, pese a su aparente precisión, la propuesta de identificar la racionalidad con la maximización se resiste a adquirir un contenido realmente preciso.

Este ejemplo no es la excepción, sino la regla. Otras propuestas de formular con precisión los preceptos del método se enfrentan con la misma dificultad. Ahora bien, si recordamos que, como lo exige con razón Popper, una condición fundamental de la refutabilidad de una teoría -es decir, de la posibilidad de "ponerla en cuestión" seriamente- es que tenga un contenido preciso, empezamos a comprender una de las maneras en que la teoría de la racionalidad como método se atrinchera, tornándose en realidad irrefutable. Simplemente se refugia en una noción esencialmente vaga de «método». Frente al fracaso de cada una de las formulaciones más o menos precisas del método racional, la racionalidad metódica no renuncia a su autodefinición. ${ }^{28}$ Lo que hace es pasar a caracterizaciones cada vez más etéreas del contenido de esa autodefinición, a una concepción de la Razón cada vez más «fina», más inefable, hasta convertirla en una mera potencia: "puissance de s'assouplir indéfiniment pour créer des instruments de mieux en mieux adaptés a une investigation toujours plus subtile de données plus complexes" (Brunschvicg, 1950 , p. 10) ${ }^{29}$ De esa manera, la debilidad misma de la razón concebida como método, su indefinibilidad misma, se transforma en un velo protector en realidad inexpugnable, y en fuente de su recobrada arrogancia. Pues, cacaso no es arrogante creer que, aun si no sabemos (y tal vez no podamos saber) en qué consiste el método racional, sí sabemos con seguridad que se puede autoperfeccionar indefinidamente, y que se puede aplicar a la solución de todos nuestros problemas presentes $y$ futuros, pequeños y grandes? ${ }^{30}$ 
Quisiera que este análisis crítico de la arrogancia de la Razón fuera leído como una crítica "interna» a la Razón, como una crítica bien intencionada, constructiva - llámesela como se desee- dirigida a preservar lo que hay de ubueno" en la noción de racionalidad. Pues no quiero de ninguna manera ponerme al servicio de los enemigos de la Razón, que desean ante todo negarla totalmente, suprimirla integralmente del mapa. Pero ¿quiénes son los enemigos de la Razón sino los dogmáticos, aun si su intransigencia arrogante se abriga bajo el título honorífico "Racional»? Sin duda es un escándalo que los enemigos declarados de la Razón se sirvan de su nombre, ${ }^{31}$ pero no menos escandaloso es que lo hagan con arrogancia sus amigos declarados. Podría parecer que, al igual que las demás oposiciones demolidas por los posmodernos, tampoco la distinción amigo/enemigo puede servirnos de refugio. A lo mejor debemos entonces, con humildad, contentarnos con iniciar y terminar nuestra labor intelectual diaria con una oración silenciosa: «¡Oh Razón, ayúdame a no usar tu nombre en vano!».

\section{NOTAS}

1. Esta expresión la tomo de la introducción de Rorty et al. (1984), que la emplean para describir un tipo ideal de historia de las ideas, no comprometido con interpretaciones y valoraciones. Como Rorty y sus coautores, no creo en la posibilidad de realizar ese ideal. Al buscar en la historia de las ideas ocurrencias de la arrogancia de la Razôn soy deliberadamente selectivo y tendencioso. Cumplo así su exigencia de tratar de escribir la historia en forma "autoconsciente". Mi tendenciosidad consiste en querer mostrar que el relativismo contemporáneo no ha sido el primero, y probablemente no será el último, en denunciar la arrogancia de la Razón.

2. Frente a los antropólogos que sostienen que el mito tiene, como la ciencia, la función de explicar o tornar inteligibles fenómenos o nociones «vagas y dificiles como las de la Creación, la Muerte, la difcrcnciación de razas», etc., afirma categóricamente Malinowski (1958, p. 43): «En sus mitos, los melanesios no quieren "explicar" ni "hacer inteligible" cosa alguna, menos aún una idea abstracta. De ello no es dable encontrar, que yo sepa, ningún ejemplo ni en Melanesia ni en ninguna otra comunidad salvaje». Tampoco, según él, son los mitos «simples narraciones, una ocupación intelectual de los primitivos» (p. 45). No es la falta de familiaridad con ciertos fenómenos y nociones o la curiosidad intelectual lo que le da al mito su papel central en las culturas primitivas, sino el hecho de que "para los nativos constituyen la afirmación de una realidad primera, más grande e importante, por la cual se determina la vida actual, el destino y la actividad del género humano, y porque su conocimiento fundamenta los actos morales y rituales del hombre y le señala cómo ha de practicarloss (p. 42). Ya para un historiador de las ideas o de las kedades de la inteligencias como Brunschvicg, el mito sí es una especie de preciencia en que se manifiesta el deseo de comprender y explicar. Pero se distingue de la ciencia por suministrar una uexplication harmonieuse et totale" (Brunschvicg, 1953, p. 35): "le primitif [...] habite un univers infinitement plus intelligible à ses yeux que notre univers ne peut l'être pour un savant du xxème sièclem (p. 21). Lo que le falta a quien se encuentra en ese "état d'enfance intellectuelle» es el instrumento critico, la capacidad de poner en duda las explicaciones "evidentesn (a sus ojos), explicaciones en que lo sobrenatural (o. lo que da lo mismo para Bruns- 
chvicg, lo trascendental) se mezcla insensible e indisolublemente con el "cours ordinaire des choses qu'il régit et qu'il expliques (p. 33). La ciencia sólo se separa definitivamente del mito cuando abandona ese "préjugé de l'intelligibilités.

3. "[...] avec Socrate et Platon, avec Democrite et Aristote, nous atteignons un moment d'apogée, ou la philosophie, sûre d'elle-même et des ses méthodes, pretend appuyer sur la raison même son droit a être l'universelle conductrice des hommes [...]" (Bréhier, 1948, t. I, fasc. 1, p. 88 ).

4. Compárese esta actitud con aquella expresada por el empleo de la frase "As far as I know...* por varios filósofos contemporáneos que trabajan en los centros uprivilegiados» del quehacer filosófico, es decir, Oxford y Cambridge (Inglaterra), Cambridge (Massachum setts), Berkeley/Stanford (California) y unos pocos más.

5. "Les siècles n'ajouteront rien a la plénitude du sens que l'arithmétique pythagoricienne confere au mot de Vérité. Pouvoir le prononcer sans risquer de fournir prétexte à équivoque ou à tricherie, sans susciter aucun soupçon de restriction mentale ou d'amplification abusive, c'est le signe auquel se reconnaîtra l'homo sapiens, définitivement dégagé de Thomo faber, porteur desormais de la valeur qui est appelée a juger de toutes les valeurs, de la valeur de vérités (Brunschvicg, 1950, pp. 2-3).

6. Independientemente de aceptarse o no las tesis de Hobbes o de Leibniz al respecto (cfr. Dascal, 1987), o de la llamada «teoría computacional de la mente» (cfr. Pylyshyn, 1984).

7. La «cuantificación» o el empleo de «modelos maternáticos» serían ejemplos de lo que llamo "aplicación". La "axiomatización" o la "formalización" en general serían ejemplos de «imitación». En ambos casos se trata de obtener, en otros campos, lo que se considera valioso en las matemáticas y por ende paradignaático de lo racional: rigor, precisión, veracidad, objetividad, predictibilidad, certidumbre, etc.

8. Berkeley, en The Analyst, critica "internamentes la falta de fundamento del cálculo infinitesimal newtoniano (debo esta observación a Menachem Fish). Se podría también mencionar como problema "internon serio de las matemáticas el hecho de que hoy día se ha departamentalizado en centenares de subdisciplinas tan distintas que los mismos matemáticos no pueden abarcarlas todas y comprender sus lenguajes. Esas subdisciplinas se han tornado asi prácticamente «inconmensurables». En esas condiciones, creer que todas emplean un mismo aestándar» de racionalidad es nada más que un acto de fe (cfr. Davis y Hersh, 1984, pp. 21-23).

9. Burnet (1908, pp. 118-121), al contrario de Brunschvicg, se esfuerza por restringir el ámbito de la supuesta tesis pitagórica de que todas las cosas son números. Según él, el indubitable descubrimiento hecho por Pitágoras de la naturaleza aritmética de la armonía musical hubiera llevado a sus discípulos o a la imaginación popular a generalizar: "Si los sonidos pueden ser reducidos a números, ¿por qué no todas las otras cosas?». Efectivamente en los pitagóricos tardíos se encuentran innumerables «teorías fantásticas" basadas en analogías entre cosas y números. Sin embargo, el sobrio testimonio de Aristóteles nos permite atribuirle a Pitágoras nada más que la tesis de que algunas cosas se explican por números, aunque entre esas cosas figuran la identificación del número 7 con el ubuen momento" (kainós), del 4 con la justicia, y del 5 con el casamiento (la suma de 2, el primer número par, identificado con lo fernenino, y 3 , el primer número impar, identificado con lo masculino). De todas maneras, según Burnet, la cosmologia pitagórica es sólo marginalmente "aritmológica», y sus tesis centrales (p. e., la existencia de un soplo ilimitado fuera de los cielos, que es inhalado por el mundo) son más bien semejantes a las de la escuela de Mileto.

10. Hipotiposis, I. 13. Empleo aquí la traducción cuidadosa de M. Burnyeat (1984, p. 229).

11. Exercitationes paradoxicae adversus Aristoteleos, Disertación Sexta, \#1. Citado segun la traducción de R. Popkin (ed.), The Philosophy of the 16th and 17th Centuries, Nueva York, The Free Press, 1966, p. 112.

12. "The secrets of nature, of things-in-themselves are forever hidden from us. But, at 
the same time, the sceptics have also gone too far. [...] Even the sceptics agree that we know appearances. But, also, we are capable of knowing something about the nature of reality by means of the criteria by which we can discern a type of indicative sign. The senses allow us to know the visible or apparent sign, and our reason enables us to interpret it, and thereby discover the hidden unperceived object. Though the senses are sometimes unreliable and erroneous, by careful reasoning we can correct their errors. [...] The sceptical quibbles about the value and foundation of reasoning are of no importance, since there are certain unquestioned principles of reasoning which are sufficiently evident to use as a basis for our inferences (Popkin, 1979, p. 142; basándose en Gassendi, Opera, vol. I, pp. 81-86).

13. Apud Bernal (1959, pp. 415-416).

14. Parallele des Anciens et des Modemes, apud Rudolf Eucken, Geistige Strömungen der Gegenwart, Leipzig, Veit y Comp., 1909, p. 276n.

15. Otras estrategias importantes en la argumentación filosófica (p. e., el intento de atribuir el onus probandi al adversario, la disputa sprevias sobre la determinación del status quaestionis, etc.) se apoyan también en la aceptación de las reglas de la disputatio. Para el uso que de ellas hace Leibniz en su controversia con Bayle, véase Dascal (1987, pp. 117-120). Para su empleo en la controversia entre Amauld y Malebranche, vease Dascal [en prensa].

16. "I would go as far as to assert that any, even the most strikingly unbelievable, from of structure and behavior can be understood, at least in principle, as the outcome of the selection pressure exerted by their particular survival function" (Lorenz, 1965, p. X).

17. «Il y a donc deux interprétations de l'interprétation, de la structure, du signe et du jeu. L'une cherche a déchiffrer, rêve de déchiffrer une vérité ou une origine échappant au jeu et à l'ordre du signe, et vit comme un exil la nécessité de l'intexprétation. L'autre, qui n'est plus tournée vers l'origine, affirme le jeu et tente de passer au delà de l'homme et de l'humanisme, le nom de lhomme étant le nom de cet être qui [...] a rêvé la présence pleine, le fondement rassurant, l'origine et la fin du jeu» (Derrida, 1967, p. 427).

18. Cfr. también: "[...] lo que yo ansío es sustituir la historia de los descubrimientos del conocimiento por las transformaciones del entendimiento» (p. 28); "Es una cuestión de transformación colectiva y compleja del entendimiento médico en su práctica y en sus reglas" (p. 29); «Y cuando uno ve cómo se desarrolló el conocimiento europeo, que resultó ser un entendimiento amplio y universal en sentido histórico y geográfico, zpuede decirse que ha habido crecimiento? Yo, por mi parte, diria que ha sido más bien una cuestión de transformación» (p. 37).

19. Por ejemplo, Rorty (1979) ha argumentado que todo argumento trascendental es fundacional, y por to tanto sujeto a las mismas criticas que se aplican a todas las formas del fundamentalismo. Frente a lo que Margolis (1984) trata de mostrar la posibilidad -y la necesidad para la ciencia - de un trascendentalismo no fundacional.

20. [...] to understand transcedental idealism we must understand the special nature of the investigation that endows the idealism with transcedental and not merely empirical status, and to understand how such a special kind of investigation is even possible we must see that idealism, understood transcendentally, is true* (Stroud, 1984, p. 160).

21. "Pero los conceptos puros del entendimiento comparados con las intuiciones empíricas (o sensibles en general) son por completo heterogéneos, desemejantes, y no se encuentran nunca en intuición alguna. ¿Cómo entonces cs posible la subsunción de esas intuiciones bajo esos conceptos, y por consiguiente la aplicación de las categorias a los fenómenos, puesto que nadie puede decir que tal categoria, por ejemplo la causalidad, se percibe por los sentidos y que está contenida en el fenómeno?» (CRP, p. 148, A 137).

22. Aun los comentadores, como Chipman (1982), que tratan de reconstruir la doctrina favorablemente reconocen su problematicidad. Nótese que también la explicación de la aplicabilidad de los mismos conceptos empiricos en términos de uhornogeneidad" es pro blemática. Además, los conceptos empíricos presentan otros graves problemas internos para la doctrina de Kant, problemas ésos conectados, a su vez, con la ausencia en Kant de una filosofía del lenguaje (véase Dascal y Senderowicz, en prensa). 
23. Véase, por ejemplo, cualquiera de las listas de beneficios de la Characteristica Universalis (o de sus otros proyectos "metódicos"), abundantes en la obra de Leibniz (p. e., en los Opuscules et Fragments Inédits, editados por L. Couturat).

24. En su discusión de la concepción de racionalidad práctica de Mosterín, Javier Muguerza (1986) se hace eco de Weber cuando subraya el peligro de la imposición de la hegemonia de la razón instrumental en nuestra civilización, señalando los "estragos» que eso puede causar (p. 21), y argumentando que ese tipo de racionalidad es, además, insuficiente para la ética. El «algo más» necesario para una verdadera ética o teoría de la razón práctica tendría que venir también de la Razón, pero no puede venir de una razón puramente "formal" o "metódicas, sino solamente de una Razón más substancial.

25. Nótese que las consideraciones «a largo plazo», que incluyen la noción de probabilidad (que, según Reichenbach, de hecho se refiere a una frecuencia relativa en un periodo largo), no son de por sí suficientes para seleccionar como sracional» la altemativa de mayor probabilidad de exito en un único caso irrepetible (cfr. Putnam. 1988).

26. "Es evidente que cuanto hemos dicho del método racional se aplica también al contenido del presente escrito. Las nociones un tanto vagas e imprecisas que aquí se han utilizado han de ser sustituidas por un aparato conccptual más riguroso y refinado. La consideración de casos simples y triviales ha de ser ampliada a casos más complejos y dificiles. Las afirmaciones y propuestas que aqui se han hecho han de ser puestas en cuestión y criticadas” (Mosterín, 1987, p. 38).

27. Para una discusión de este problema, y de la necesidad que acarrea de contentarnos con explicaciones de la acción humana que no son ni óptimas ni subóptimas, sino "satisficing", véase Elster (1988). A mi entender, Elster tendria que llegar, a partir de problemas como ése, a un cuestionamiento más radical del modelo de explicación racional propuesto por la teoria de la decisión (cfr. Dascal, 1988b).

28. En forma semejante, el fracaso rotundo de todas las propuestas de formalización del "principio de verificación" en nada ha avalado la confianza de los neopositivistas en que ese principio expresa algo que no puede no ser verdadero (cfr. Dascal, 1971).

29. Compárese esa noción con la noción, igualmente inefable e inatacable, de uperfectibilidad" que, scgín Rousseau, es una de las propiedades que distinguen fundamentalmente al hombre de los animales. Esa propiedad antecede a la razón o al ontendimiento, siendo más bien lo que le permite al hombre desarrollarlos (Rousseau, 1754, pp. 65 y 109).

30. Véase, por ejemplo, la recomendación de Mosterín (1987, pp. 60-61) de no contentarse con la racionalización parcial de algunos aspectos de nuestra cultura, dejando otros "en la inerte penumbra de la tradición», sino de ir más allá, intentando la "total racionalización” de la cultura.

31. Brunschvicg (1953, p. 14) considera (con razón) un «scandale» el hecho de que Jacobi, sl'un des protagonistes de la réaction romantique, plus fidele que jamais au primat de lintuition sentimentale", tenga el desplante de "designer sous le nom de raison une faculté d'absolu, métacritique et anticritique, et lui demander d'alimenter le courant d'irrationalisme qui devait emporter le 19 ème siècle et qui demeure a certains égards un des caractères saillants de la pensée contemporaine».

\section{BIBLIOGRAFÍA}

AYeR, AlFRed J.: Language, Truth and Logic, Londres, V. Golancz, 1946.

BerNal, JoHn D.: La ciencia en la historia, México, Universidad Nacional Autónoma de MéxiCo, 1959.

BréhIER, ÉMTL: Histoive de la Philosophie, París, Presses Universitaires de France, 1948, 5. $\mathrm{ed}$. 
Brunschulc, Leon: Héritage de Mots, Hénitage d'Idées, París, Presses Universitaires de France, 1950.

-: Les Ages de l'Intêlligence, París, Presses Universitaires de France, 1953, 4." ed.

BuRNeT, JoHn: Early Greek Philosophy, Londres, Adam and Charles Black, 1908.

BurNYeAt, Mtifs F.: 1984. "The sceptic in his place and time", en Rorty et al. (eds.) 225254.

CIIPMAN, LALCHLAN: "Kant's categories and their schematism", en R.C.S. Walker (ed.): Kant on Pure Reason, Oxford, Oxford University Press, 1982, 100-116.

CHOMSKY, NoAM y FoUCAULT, Michel: La naturaleza humana: ijusticia o poder?, Valencia, Cuadernos Tcorema, 1976.

DASCal, Marcelo: "Empirical significance and relevance", Philosophia, 1 (1971), 81-106.

- Leibniz: Language, Signs and Thought, Amsterdam/Filadellia, John Benjamins, 1987.

-: "Reflexiones sobre la "crisis de la modemidad", Crítica XX, 58 (1988a) 3-42.

-: "Rational-choice explanation: the limits to grounding», en E. Ulman-Margalit (ed.), $1988 b, 67-79$.

-: :The controversy about ideas and the ideas about controversy", en F. Gil (ed.): Controvérsias Científicas e Filosóficas, Lisboa, Editorial Fragmentos, en prensa.

- y SENDEROWICZ YaRON: "Lenguaje y pensamiento en la epistemología de Kant", Iyyun, en prensa (en hebreo).

Davis, PhIIP J. y Hersh, Reuben: The Mathematical Experience, Hardmonswarth, Penguin Books, 1984.

DERRIA, JACQUES: L'Écriture et la Différence, París, Seuil, 1967.

ELSTER, JON: "The nature and scope of rational-choice explanation», en E. Ullman-Margalit (ed.), 51-65.

Granger, Gilles-Gaston: La Raison, París, Presses Universitaires de France, 1958.

Hemegger, M.: "Die Frage nach der Technik», en Die Technik und die Kehre, Pfüllingen, Neske, 1962, 5-36.

KAnt, IMMANuel: Kritik der reinen Vemunft, 1787, 2. ed. (trad. esp. de José del Perojo, Buenos Aires, Sopena, 1952. Abrevio esta traducción por CRP; «A» se refiere a la paginación de la primera edición alemana, y «B» a la de la segunda).

Lévi-Strauss, Claude: La Pensée Sauvage, París, Plon, 1962.

LORENZ, KONRAD: "Preface*, en Charles Darwin: The Expression of the Emotions in Man and Animals, Chicago, The University of Chicago Press, 1965, DX-XIII.

Malinowska, Bronislaw: Estudios de psicologia primitiva, Buenos Aires, Paidós, 1958.

-: "The problem of meaning in primitive languages", en C.K. Ogden y I.A. Richards; The Meaning of Meaning, Londres, Routledge and Kegan Paul, 1969, 10. ed., 296-335.

MaRgous, JosepH: "Scientific realism as a transcendental issue", Manuscrito .7, 1-2 (1984), 87-107.

Mosterin, Jesus: Racionalidad y acción humana, Madrid, Alianza, 1987, 2. ${ }^{\text {a }} \mathrm{ed}$.

MUGUERZA, JAVIER: «Humán, demasiado humán; o la astucia de la razón instrumental», Arbor 125,490 (1986), 9-28.

Olaso, Ezeouiel de: "Zetesis», Manuscrito, 11, 2 (1988), 7-32.

POPKIN, RichaRd H.: The History of Scepticism from Erasmus to Spinoza, Berkeley, University of California Press, 1979.

Putnam, Hilary: «Racionalidad en la teoría de la decisión y en la ética», en L. Olivé (ed.); Racionalidad, México, Siglo XXI, 1988.

Pylysmin, Zenox W.: Computation and Cognition: Toward a Foundation for Cogmitive Science, Cambridge, Mass., The MTT Press, 1984.

RORTY, RrCIARD: "Transcendental arguments, self-reference, and pragmatism», en P. Bieri et al. (eds.); Transcendental Arguments and Science, Dordrecht, Reidel, 1979, pp. 77-103.

-, SchneEWInd, J.B. y Skinner, Quentin (eds.): Philosophy in History, Cambridge, Cambridge University Press, 1984. 
Rousseau, JeAN-Jacoues: Discotirs sur lorigine de linégalité pami les hommes et si elle est autorisée par la loi naturelle, 1754 en Du Contrat Social (y otros escritos), París, Gar: nier, 1954.

STROUd, BarRY: The Significance of Philosophical Scepticism, Oxford, Clarendon Press, 1984. Ullman-Margalit, E. (ed.): Science in Reflection, Dordrecht, Kluwer, 1988.

WrTrGensteIN, LuDWT: Über Gewissheit - On Certainty, trad. de G.E.M. Anscombe y G.H. von Wright, Oxford, Blackwell, 1969. 